\title{
Study of the Relationship between Vitamin D Level and the Increase in the Severity of Covid-19 Infection in Kirkuk City
}

\author{
Muhannad Abdullah Al-Azzawy ${ }^{1}$, Staar Mohammed Qader², Ali Adnan Mirdan ${ }^{3}$

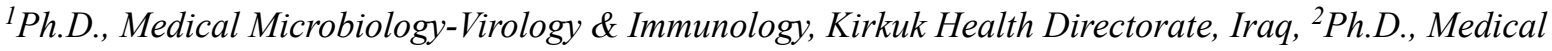 \\ Microbiology-Virology. College of Medical Technology. AL-Kitab University. Kirkuk, ${ }^{3}$ Ph.D., Clinical \\ Biochemistry. Kirkuk Health Directorate, Iraq
}

\begin{abstract}
The study aimed to find the relation between Covid-19 infection and reduction in vitamin-D levels and with development of severe infection The study was conducted in Kirkuk city during July 2020, included 120 COVID-19 patients who diagnosed by collecting of naso/oropharyngeal swabs and the virus RNA was qualitatively detected by real-Time PCR in Public Health Laboratory according manufacture instruction and WHO protocol. The study also included 30 healthy persons as control group. The study included the collection of blood samples for determination of vitamin-D level (I-chroma, Korea) by direct immunofluorescence technique and according to manufacture instruction. The study also included collection of associated information like age, sex, residence, BMI and by contacting with all patients daily until the $10^{\text {th }}$ day of infection to know their status after treatment. The study showed that, majority of patients were aged from 22 to 41 years of old (P. value $<0.001$ ). The study showed that $62.5 \%$ of COVID-19 patients were males compared with $37.5 \%$ females $(\mathrm{P}<0.05)$. The study showed that were asymptomatic, $44.17 \%$ of cases of COVID-19 patients were with mild infection and $10 \%$ were with severe infection $(\mathrm{P}<0.001)$. The study showed a significant relation between Covid-19 infection status with age as the highest mean of age of Covid-19 infected patients was recorded in those who with severe infection. The study showed that the lowest mean of serum Vitamin was found in COVID-19 patients comparing with healthy control (12.8 \pm 3.6 v.s. $29.3 \pm 3.1 \mathrm{ng} / \mathrm{ml})(\mathrm{P}:<0.001)$. The study also demonstrated that the level of vit. D was significantly reduced in severe infected COVID-19 patients followed by patients with moderate infection and the highest mean was in patients with asymptomatic infection $(\mathrm{P}<0.001)$.
\end{abstract}

Keywords: Covid-19; Severe infection; PCR; Kirkuk; Vitamin D.

\section{Introduction}

The Covid-19 virus is one of the modern viruses that have spread in our societies since the beginning of 2020 and up to this point ${ }^{(1)}$. The spread of this virus in the community is considered one of the most dangerous viruses on the soul of humans, especially in later ages, and for people with chronic diseases, diabetes, hypertension, acute pneumonia, cancer, and chronic kidney inflammation ${ }^{(2)}$. This virus has spread to all countries of the world, including the Middle East, the Republic of Iraq, especially in the city of Kirkuk and Baghdad, and from the south and the cities of Iraqi Kurdistan ${ }^{(3)}$. Among the most common elements and causes of the spread of this disease is the failure to respond to the laws of the World Health Organization and the Ministry of Health in terms of social distancing, wearing masks, sterilizing feet, surfaces and floors, and avoiding touching, kissing and shaking hands ${ }^{4)}$. Epidemiological studies investigating links between circulating levels of 25 -hydroxyvitamin D $(25[\mathrm{OH}]$ $\mathrm{D}$; the biomarker of vitamin $\mathrm{D}$ status) and incidence and severity of COVID-19 are currently limited in number. Two ecological studies have reported inverse correlations between national estimates of vitamin D status and COVID-19 incidence and mortality in European countries. Lower circulating 25(OH)D concentrations have also been reported to associate with susceptibility to SARS-CoV-2 infection and COVID-19 severity ${ }^{(5)}$. Recently, we have shown that airway diseases are associated with dysregulated vitamin D metabolism raising the possibility that vitamin $\mathrm{D}$ deficiency might 
arise as a consequence of pulmonary inflammation. Prospective studies can provide insights into the potential for reverse causality, but results from those published to date are conflicting: one retrospective longitudinal study from Israel reported independent associations between low pre-pandemic 25(OH)D levels and subsequent incidence and severity of COVID-19 ${ }^{(6-10)}$. The study aimed to find the relation between Covid-19 infection and reduction in vitamin-D levels and with development of severe infection

\section{Materials and Method}

The study was conducted in Kirkuk city during July 2020, included 120 COVID-19 patients who diagnosed by collecting of naso/oropharyngeal swabs and the virus RNA was qualitatively detected by real-Time PCR in Public Health Laboratory (Sacace Biotechnology, Italy) according manufacture instruction and WHO protocol. The study also included 30 healthy persons as control group. The study included the collection of blood samples for determination of vitamin-D level (I-chroma, Korea) by direct immunofluorescence technique and according to manufacture instruction. The study also included collection of associated information like age, sex, residence, BMI and by contacting with all patients daily until the $10^{\text {th }}$ day of infection to know their status after treatment.

\section{Results}

The study showed that, majority of patients were aged from 22 to 41 years of old ( $\mathrm{P}$. value $<0.001$ ), Table 1.

Table 1: Distribution of studied patients according to characteristics of menstrual cycle

\begin{tabular}{|c|c|c|}
\hline Age (Year) & No. & $\mathbf{\%}$ \\
\hline $12-21$ & 12 & 10 \\
\hline $22-31$ & 28 & 23.33 \\
\hline $32-41$ & 40 & 33.33 \\
\hline $42-51$ & 20 & 16.67 \\
\hline $52-61$ & 11 & 9.17 \\
\hline $62-71$ & 9 & 7.5 \\
\hline Total & $\mathbf{1 2 0}$ & $\mathbf{1 0 0}$ \\
\hline
\end{tabular}

P. value $<0.001$

The study showed that $62.5 \%$ of COVID- 19 patients were males compared with $37.5 \%$ females $(\mathrm{P}<0.05)$, Table 2 .
Table 2: Distribution of Covid-19 according to sex

\begin{tabular}{|l|c|c|c|}
\hline \multirow{3}{*}{ P.value } & \multicolumn{2}{|c|}{ Positive } & \multirow{2}{*}{ Sex } \\
\cline { 2 - 3 } & $\mathbf{\%}$ & No. & \\
\hline \multirow{3}{*}{0.026} & 62.5 & 75 & Male \\
\cline { 2 - 4 } & 37.5 & 45 & Female \\
\cline { 2 - 3 } & 100 & 120 & Total \\
\hline
\end{tabular}

The study showed that were asymptomatic, $44.17 \%$ of cases of COVID-19 patients were with mild infection and $10 \%$ were with severe infection $(\mathrm{P}<0.001)$, Table 3 .

Table 3: Distribution of Covid-19 according to type of infection

\begin{tabular}{|l|c|c|}
\hline Covid-19 cases & No. & \% \\
\hline Asymptomatic & 30 & 25 \\
\hline Mild & 53 & 44.17 \\
\hline Moderate & 25 & 20.83 \\
\hline Severe & 12 & 10 \\
\hline Total & $\mathbf{1 2 0}$ & $\mathbf{1 0 0}$ \\
\hline
\end{tabular}

P. value $<0.001$

The study showed a significant relation between Covid-19 infection status with ageas the highest mean of age ofCovid-19 infected patients was recorded in those who with severe infection

Table 4: Relation of Covid-19 infection status with age

\begin{tabular}{|l|c|c|}
\hline Covid-19 cases & Mean \pm SD & P. value \\
\hline Asymptomatic & $30.55 \pm 4.5$ & \\
\cline { 1 - 2 } Mild & $32.17 \pm 4.7$ & \multirow{2}{*}{$\mathrm{P}<0.001$} \\
\cline { 1 - 2 } Moderate & $40.15 \pm 4.9$ & \\
\hline Severe & $58.5 \pm 5.4$ & \\
\hline
\end{tabular}

The study showed that the lowest mean of serum Vitamin was found in COVID-19 patients comparing with healthy control $(12.8 \pm 3.6$ v.s. $29.3 \pm 3.1 \mathrm{ng} / \mathrm{ml})(\mathrm{P}$ : $<0.001)$.

Table 5: Levels of vitamin D in COVID-19 patients and the control group

\begin{tabular}{|l|c|c|c|}
\hline Group & Mean $(\mathbf{n g} / \mathbf{m l})$ & SD & P value \\
\hline COVID-19 patients & 12.8 & 3.6 & \multirow{2}{*}{$<0.001$} \\
\cline { 1 - 3 } Healthy group & 29.3 & 3.1 & \\
\hline
\end{tabular}


The study also demonstrated that the level of vit. D was significantly reduced in severe infected COVID-19 patients followed by patients with moderate infection and the highest mean was in patients with asymptomatic infection $(\mathrm{P}<0.001)$, Figure 1 .

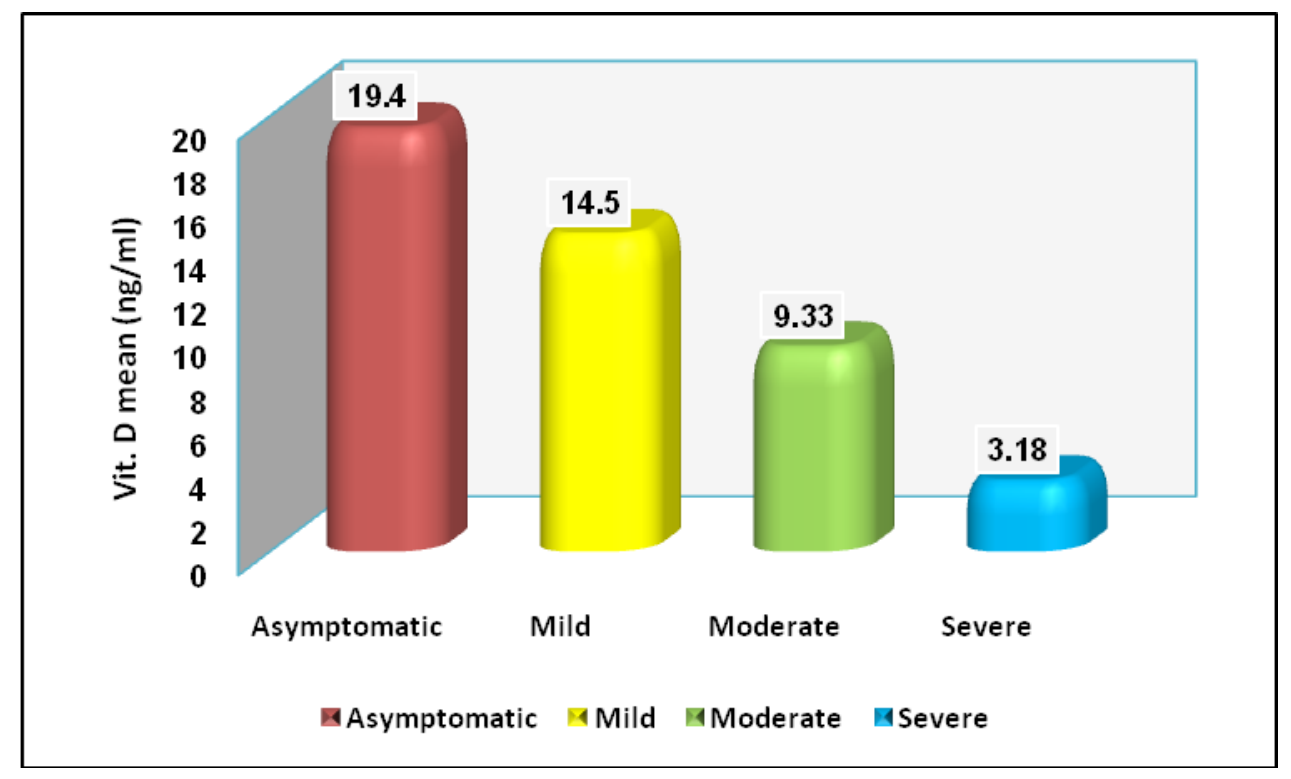

Figure 1: relation of Vit. D and severity of Covid-19 infection

\section{Discussion}

Numerous studies have found that the Covid-19 virus is spreading highly in eastern and Middle Eastern countries in Saudi Arabia, Iraq, Iran, Turkey and the Arab Gulf. Covid-19 and those with symptoms similar to those of Covid-19 were actually infected with the virus in this study ${ }^{6}$. And as our study found, the most people infected with the Covid-19 virus are among the people who spend cities, and as such, numerous studies were conducted at the beginning of this year and to the end of this day, as studies indicated that those who say cities are the most vulnerable to infection with covid 19, and there is no doubt ${ }^{7-10}$. Many studies conducted previously that young people are the most vulnerable to infection due to their frequent interaction with infected people, caring for the sick and suffering from health personnel or Of the people who provide services to the community, all the restaurants, clothes, shops, laboratories, and factories, all of them are young cadres who may be exposed to people infected with covid-19 and they do not know, then they may be infected, then they go to health centers, and then it is discovered that they are infected with Covid $19^{11,12}$. Our findings about the increased risk of testing positive for COVID-19 with likely deficient vitamin D status compared with likely sufficient vitamin D status contrasts with the findings of a recent study by $\mathrm{Xu}$ et al ${ }^{13}$. Since vitamin $\mathrm{D}$ deficiency may be increased by many factors that could be associated with COVID-19 risk, including age, obesity, diabetes, and chronic illness more generally, observed associations of vitamin D with outcomes in almost any observational study may fail to accurately reflect any potential causal effects of vitamin D on outcomes. Some clinical and epidemiological studies support to outline the hypothesis regarding COVID-19 and its relationship with vitamin D status. Recent studies indicated that COVID-19 is associated with low vit $\mathrm{D}$ level ${ }^{11,14}$. In other studies, serum concentrations of $25(\mathrm{OH}) \mathrm{D}$ were inversely associated with pro-inflammatory cytokines, IL-6, increased CRP, and increased risk of pneumonia, ARDS, diabetes and heart failure. In randomized control trials, vitamin D supplementation has been shown to reduce the risk of respiratory diseases ${ }^{15,16}$. A placebo-controlled trial with 5660 subjects showed that vitamin D supplementation significantly reduces the risk of respiratory tract infections 17. A review included five clinical studies reported that respiratory tract infections were significantly lower in the vitamin D supplementation group than the control group 18. Another study included 25 randomized controlled trials, with 10,933 participants in total from 14 different countries indicated the beneficial effects of vitamin D 
supplementation in reducing the risk of at least one acute respiratory tract infection ${ }^{19}$.

\section{Conclusions}

There was a significant relation between vitamin-D reduced levels and severity of Covid-19 infection

Financial Disclosure: There is no financial disclosure.

Conflict of Interest: None to declare.

Ethical Clearance: All experimental protocols were approved under the Kirkuk Health Directorate and all experiments were carried out in accordance with approved guidelines.

\section{References}

1. Tektook NK, Yadav PR, Alazzawy MA. Prevalence Corona Virus Disease 2019 (COVID-19) in Baghdad City. International Journal of Advances in Medical Sciences. 2020 Oct 5:01-6.

2. Shaw AC, Goldstein DR, Montgomery RR. Agedependent dysregulation of innate immunity. Nat Rev Immunol 2013; 13:875-87.

3. Moro-García MA, Alonso-Arias R, López-Larrea C. When aging reaches CD4+ T-cells: phenotypic and functional changes. Front Immunol 2013; 4:107.

4. Ilie PC Stefanescu S Smith L

5. The role of vitamin $\mathrm{D}$ in the prevention of coronavirus disease 2019 infection and mortality. Aging Clin Exp Res. 2020; 32: 1195-1198

6. D'Avolio A Avataneo V Manca A et al. 25-hydroxyvitamin D concentrations are lower in patients with positive PCR for SARS-CoV-2. Nutrients. 2020; 12e1359

7. Panagiotou G Tee SA Ihsan $\mathrm{Y}$ et al. Low serum 25-hydroxyvitamin D (25[OH]D) levels in patients hospitalised with COVID-19 are associated with greater disease severity. Clin Endocrinol (Oxf). 2020; (published online July 3.)

8. Jolliffe DA Stefanidis C Wang Z et al. Vitamin D metabolism is dysregulated in asthma and chronic obstructive pulmonary disease. Am J Respir Crit Care Med. 2020; (published online March 18.)

9. Merzon E Tworowski D Gorohovski A et al. Low plasma $25(\mathrm{OH})$ vitamin D level is associated with increased risk of COVID-19 infection: an Israeli population-based study. medRxiv. 2020; (published online July 3.) (preprint)

10. Wan S, Xiang Y, Fang W, Zheng Y, Li B, Hu Y, et al. Clinical features and treatment of COVID-19 patients in northeast Chongqing. J Med Virol. (Wan, Xiang, Fang, Li, Hu, Lang, Huang, Sun, Xiong, Huang, Lv, Shen, Yang, Huang, Yang) Pharmaceutical Department of Chongqing Three Gorges Central Hospital, Chongqing University Three Gorges Hospital, Chongqing 404100, China: NLM (Medline); 2020

11. Wang Z, Yang B, Li Q, Wen L, Zhang R. Clinical Features of 69 Cases with Coronavirus Disease 2019 in Wuhan, China. Clin Infect Dis. (Wang, Li, Wen, Zhang) Cancer Center, Union Hospital, Tongji Medical College, Huazhong University of Science and Technology, Wuhan, China: NLM (Medline); 2020

12. Liu K, Chen Y, Lin R, Han K. Clinical features of COVID-19 in elderly patients: A comparison with young and middle-aged patients. J Infect. (Liu) Hainan General Hospital, Geriatric center, China: W.B. Saunders Ltd; 2020; ]

13. Huang C, Wang Y, Li X, Ren L, Zhao J, Hu Y, et al. Clinical features of patients infected with 2019 novel coronavirus in Wuhan, China. Lancet. (Huang, Zhang, Yu, Xia, Wei, Wu, Xie) Jin Yin-tan Hospital, Wuhan, China: Lancet; 2020;395:497506. 10.1016/S0140-6736(20)30183-5 [PMC free article] [PubMed] [CrossRef] [Google Scholar]

14. Xu X-W, Wu X-X, Jiang X-G, Xu K-J, Ying L-J, Ma C-L, et al. Clinical findings in a group of patients infected with the 2019 novel coronavirus (SARSCov-2) outside of Wuhan, China: retrospective case series. BMJ. (Xu, Wu, Xu, Sheng, Cai, Qiu, Li) State Key Laboratory for Diagnosis and Treatment of Infectious Diseases, National Clinical Research Centre for Infectious Diseases, Collaborative Innovation Centre for Diagnosis and Treatment of Infectious Diseases, First: BMJ Publishing Group (e-mail: subscriptions@bmjgroup.com); 2020;368.

15. R.C. Dancer, D. Parekh, S. Lax, V. D’Souza, S. Zheng, C.R. Bassford, et al.Vitamin D deficiency contributes directly to the acute respiratory distress syndrome (ARDS) Thorax, 70 (2015), pp. 617-624

16. M. Manion, K.H. Hullsiek, E.M. Wilson, F. Rhame, E. Kojic, D. Gibson, et al.Vitamin D deficiency is associated with IL-6 levels and monocyte activation in HIV-infected persons PLoS ONE, 12 (2017), p. $\mathrm{e} 0175517$. 
17. D. Lu, J. Zhang, C. Ma, Y. Yue, Z. Zou, C. Yu, et al.Link between community-acquired pneumonia and vitamin D levels in older patients $\mathrm{Z}$ Gerontol Geriatr, 51 (2018), pp. 435-439

18. P. Bergman, Lindh ÅU, L. Björkhem-Bergman, J.D. Lindh Vitamin D and respiratory tract infections: a systematic review and meta-analysis of randomized controlled trials PLoS ONE, 8 (2013), p. e65835
19. J. Charan, J. Goyal, D. Saxena, P. Yadav Vitamin $\mathrm{D}$ for prevention of respiratory tract infections: a systematic review and meta-analysis J Pharmacol Pharmacother, 3 (2012), p. 300

20. A.R. Martineau, D.A. Jolliffe, R.L. Hooper, L. Greenberg, J.F. Aloia, P. Bergman, et al. Vitamin D supplementation to prevent acute respiratory tract infections: systematic review and meta-analysis of individual participant data BMJ (2017), p. 16583. 